\title{
Anaplastic astrocytoma
}

INSERM

\section{Source}

INSERM. (1999). Orphanet: an online rare disease and orphan drug data base. Anaplastic astrocytoma. ORPHA:251589

Anaplastic astrocytoma is a rare, high-grade, malignant glial tumor, histologically characterized by abundance of pleomorphic astrocytes and multiple mitotic figures, often associated with diffuse infiltration of the surrounding tissue, considerable edema and mass effect and involvement of the contralateral brain. Depending on the primary localization of the tumor, patients can present with signs of raised intracranial pressure (headache, vomiting, papilledema), seizures, progressive neurological deficits, and/or behavioral changes. The tumor is most commonly localized in the frontal and temporal lobes, brain stem and spinal cord. 